\title{
Correction to: Factors influencing medical students' choice of emergency medicine as a career specialty-a descriptive study of Saudi medical students
}

\author{
Hadeel Alkhaneen ${ }^{1}$, Faisal Alhusain ${ }^{1}$, Khalid Alshehri ${ }^{1}$ and Nawfal Al Jerian ${ }^{2 *}$
}

\section{Correction}

Following publication of the original article [1], the authors reported that one of the authors' names is spelled incorrectly. In this Correction the incorrect and correct author name are shown. The original publication of this article has been corrected.

Originally the author name has been published as:

- Khalid Alshahri

The correct author name is:

- Khalid Alshehri

\section{Author details}

'College of Medicine, King Saud bin Abdulaziz University for Health Sciences,

Riyadh, Saudi Arabia. ${ }^{2}$ Department of Emergency Medicine, Ministry of

National guard health affairs, P.O Box 86871, Riyadh 11632, Saudi Arabia.

Received: 12 November 2018 Accepted: 12 November 2018

Published online: 17 December 2018

\section{Reference}

1. Alkhaneen $\mathrm{H}$, et al. Factors influencing medical students' choice of emergency medicine as a career specialty —a descriptive study of Saudi medical students. Int J Emerg Med. 2018;11:14 https://doi.org/10.1186/ s12245-018-0174-y.

* Correspondence: nawfalaljerian@gmail.com

The original article can be found online at https://doi.org/10.1186/s12245018-0174-y

${ }^{2}$ Department of Emergency Medicine, Ministry of National guard health

affairs, P.O Box 86871, Riyadh 11632, Saudi Arabia

Full list of author information is available at the end of the article 